\title{
LA SUBJETIVIDAD HECHA NORMA: RELATOS Y SISTEMAS EN LOS NEWSGAMES O VIDEOJUEGOS INFORMATIVOS
}

\author{
THE SUBJECTIVITY MADE NORM: STORIES AND SYSTEMS IN THE \\ NEWSGAMES OR INFORMATIVE VIDEO GAMES
}

\author{
Santiago PERIBAÑEZ FAGUAS \\ Universidad Complutense de Madrid \\ santiagoperibanez@gmail.com
}

\begin{abstract}
Resumen: El relato periodístico se construye sobre un fino encaje entre la buscada objetividad y la subjetividad del sujeto creador. Los grados de relación entre ambas partes han establecido unos géneros periodísticos que han ayudado a productores y consumidores a identificar cada pieza y las características de su mensaje. Tal taxonomía no resulta completamente operativa en un nuevo entorno donde proliferan formatos tales como los newsgames o videojuegos informativos; los distintos niveles del relato videolúdico asumen y muestran de formas muy diferentes las subjetividades del proceso creativo. El presente artículo desglosa en primer lugar los recursos del videojuego informativo que pueden impregnarse de esta subjetividad y cómo es mostrada al lector final. Como apoyo a esta explicación, la segunda parte del texto recoge el análisis de uno de los newsgames más complejos desarrollados en España: Montelab, obra del Lab RTVE.
\end{abstract}

Palabras clave: Newsgames, videojuegos, periodismo, subjetividad, game design.

Abstract: The journalistic storytelling is constructed on a fine line between the desired objectivity and the subjectivity of every subject. The degrees of relationship between both of them have established journalistic genres that have helped producers and consumers identify each text and its message. Such taxonomy is not completely operative in a new environment where formats such as newsgames arise; the different levels of the videoludic story show in very different ways the subjectivities of the creative process. The present article breaks down the resources of newsgames that can be impregnated with this subjectivity and how it is shown to the final reader. To support this explanation, the second part of the text includes the analysis of one of the most complex newsgames developed in Spain: Montelab, work of the Lab RTVE.

Keywords: newsgames, videogames, journalism, subjectivity, game design. 


\section{ubjetividad y periodismo}

La objetividad del periodista es uno de los mitos fundacionales de la profesión, un compromiso que se enseña en las facultades y se repite en cada redacción como ritos fundacionales del oficio (Chillón, 1999; Tuchman, 1998). Sin embargo, en la práctica cotidiana afloran todo tipo de problemas y soluciones apresuradas que son, cuanto menos, excepciones a esta objetividad; en muchos casos, la objetividad no es sino un reparto de tiempos entre las distintas opiniones de la noticia (Canel, 1997).

Como respuesta a esta deriva, surgen voces en la estela de los conocimientos situados (Haraway, 1995) que reivindican el papel del sujeto informador en el propio relato periodístico (Aladro, 2011; San Martín, 2014). La supuesta objetividad no solo aleja a los lectores del proceso de investigación, sino que oculta los intereses políticos y empresariales que dominan el trabajo diario de los reporteros. Por tanto, «estas necesarias tomas de posición [...] no solo son inevitables sino que [...] aceptarlas y transparentarlas resulta beneficioso» (San Martín, 2014: 76).

Esta transparencia aflora en crónicas de periodistas como Martín Caparrós, cuyo cuerpo y percepción forman parte del propio relato. De esta forma, el lector puede comprender la compleja «cuestión de poder ver» (Haraway, 1995: 330) que supone la inclusión o no de actores, eventos y descripciones en la pieza periodística. Otro enfoque para solucionar el mismo problema viene de eldiario.es; sus responsables explican de forma periódica los motivos de un determinado tratamiento de cierto acontecimiento o la exclusión de otro evento.

Un problema diferente surge cuando esta transparencia no es posible debido a las propias características del medio. Por ejemplo, limitaciones de espacio en página o tiempo en antena. $\mathrm{O}$, en el caso que nos ocupa, cuando la subjetividad del autor no aparece de forma explícita sino que configura la propia 'vivencia' del relato (Aarseth, 1997): es el caso de los newsgames o videojuegos informativos.

Los newsgames son videojuegos cuya función principal no es entretener sino informar, integrándose por tanto dentro de la producción periodística (Peribañez, 2017). En estos relatos es especialmente importante la labor del creador porque no solo compone una narración, sino que crea las dinámicas de juego mediante las cuales el lector conocerá la historia (Sicart, 2008).

Debido a su singular lenguaje, el análisis sobre el videojuego informativo no puede limitarse a una inclusión explícita de la subjetividad como ocurre en otros relatos periodísticos. Para analizar la intencionalidad de un texto videolúdico debemos profundizar en los sistemas de reglas que rigen el discurso aun sin ser percibidos por el lector, puesto que «en un medio interactivo, la interpretación del mundo está encarnada en las reglas que hacen funcionar el sistema» (Murray, 1999: 100). 


\section{Metodología y objeto de estudio}

¿Cómo explicitar, pues, estas normas y analizar la subjetividad que habita en ellas? En los últimos años han surgido infinidad de propuestas de trabajo y metodologías para estudiar los videojuegos, paralelamente a la consolidación de los games studies como área de estudio. Para el caso concreto de los newsgames resulta interesante partir de las estructuras propuestas por Pérez Latorre (2011) para el análisis del lenguaje videolúdico y los modelos propuestos por Bogost (2009) consolidados en una taxonomía posterior (Peribañez, 2017).

Al analizar la estructura del lenguaje videolúdico se pueden identificar cuatro ejes fundamentales que vertebran la estructura interna del juego (Pérez Latorre, 2011: 45):

- Sujeto y entorno. Para lograr el éxito, el jugador debe inscribirse en una estructura ajena, representada por las normas del videojuego; esta tensión marca la estructura profunda de todos los juegos.

- Mundo y experiencia. Cada videojuego crea un mundo establecido por las reglas de juego, quienes determinan la experiencia del usuario y su éxito o fracaso.

- Experiencia y objetivo. En relación con el eje anterior, los usuarios se adecuan a las reglas marcadas para progresar en el juego, por lo que la experiencia de juego 'prototípica' viene marcada ya en el diseño del juego.

- Redundancia y variabilidad. Siguiendo la distinción entre ludus o juego establecido y paidea o juego libre, en todo videojuego se pueden encontrar elementos repetitivos y aleatorios.

El proceso de lectura o interacción con el videojuego se apoya en estas cuatro variables para construir un relato adaptado a las acciones realizadas por cada lector; «el jugador no solo juega al videojuego sino que también, en parte, 'es jugado' por el juego» al enmarcarse en las reglas establecidas (Pérez Latorre, 2011: 47).

Pero el análisis de los newsgames no solo debe centrarse en el lenguaje videolúdico sino que debe recoger las características propias del relato periodístico. Si estamos ante una nueva narrativa informativa, debemos poder identificar en ella algunos de los rasgos propios de este discurso. De forma similar al análisis de otros tipos de textos, el análisis del discurso periodístico se apoya en estructuras semánticas para reflejar la macroestructura o asunto del texto, así como el propio procesamiento del relato (Van Dijk, 1990: 48). Al tratarse de un videojuego, la semántica y gramática se deriva del ámbito videolúdico, pero la pragmática $\mathrm{y}$, por tanto, la macroestructura resultante pueden interpretarse directamente desde una perspectiva periodística.

En resumen, para analizar un newsgame en su totalidad debemos recurrir a una sintaxis videolúdica que permita identificar y explicar la función de las estructuras del discurso. Esta disección aportará las herramientas necesarias para plasmar la macroestructura del texto gracias a todos los procesos de enunciación que aparecen en el texto.

El objeto de estudio de esta investigación es Montela $b^{1}$, un newsgame o videojuego periodístico desarrollado por el Lab de RTVE junto con Documentos TV para explicar el modo de vida previo a la

\footnotetext{
${ }^{1}$ Montelab puede jugarse en la siguiente dirección: http:/lab.rtve.es/montelab/
} 
crisis económica de 2008 y mostrar por qué este acontecimiento tuvo repercusiones tan duras para la gran mayoría de los españoles.

La burbuja inmobiliaria en España explotó en 2008 de la mano de la crisis económica global, un periodo especialmente duro para aquellas familias que habían comprado una casa en condiciones claramente desfavorables y apenas pudieron superar este golpe. Desde entonces se han construido muchos relatos sobre la dificultad de sostener una familia con la carga de la hipoteca y, en parte, se colocó gran parte de la culpa sobre los hombros de las personas que compraron viviendas en esta situación.

Una de las piezas periodísticas que mejor ilustran las razones de estas familias es Montelab, que sitúa al lector/jugador como un ciudadano que va a comprar o alquilar vivienda antes de la crisis. Sus decisiones marcan el éxito o la quiebra frente a las dificultades económicas y sociales que afloraron en la crisis. Por eso es un buen ejemplo de las herramientas de los newsgames, además de haber sido desarrollado por RTVE.

\section{Análisis}

Al igual que otros muchos videojuegos, Montelab arranca con un vídeo de presentación que ayuda a contextualizar las acciones del juego. A diferencia de otros relatos videolúdicos, aquí no se presenta al héroe protagonista sino que se presenta cómo la crisis económica de 2008 reventó la burbuja inmobiliaria en España, dejando a miles de familias sin el hogar prometido por las compañías inmobiliarias.

El montaje de este vídeo ya presagia el tono satírico y de denuncia que tiñe cada elemento de Montelab. Esta introducción se presenta como una promoción inmobiliaria que interpela al jugador para comprar una casa; tanto la locución como la música de fondo son exageradas para subrayar la falsedad de esta propuesta. La denuncia se manifiesta a través de pequeños 'cortes' en el vídeo que, a modo de interferencia clandestina (figura 1), boicotea el discurso normativo para denunciar la realidad: las urbanizaciones con piscina y jardín dieron paso a instalaciones sin los servicios básicos, cuyo valor era muy inferior al pagado por las familias.

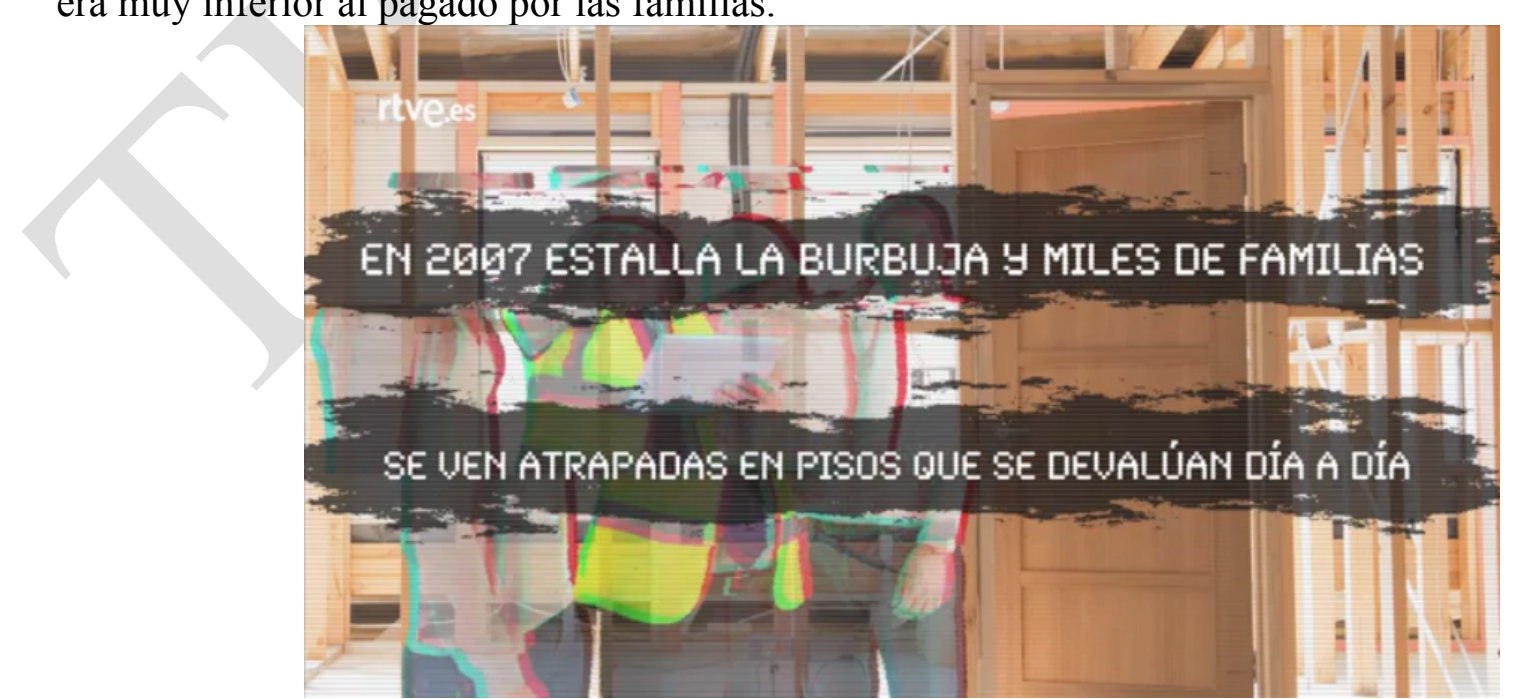

Figura 1: Captura de Montelab (RTVE.es, 2014) 
Este audiovisual resulta muy interesante desde el punto de vista periodístico puesto que, si bien se trata de una sátira, recoge todos los argumentos y premisas que caracterizaron la estrategia inmobiliaria de los años previos a la crisis. "Nuestra economía no deja de crecer, ¿va usted a dejar pasar este tren?" o "La vivienda es la mejor inversión" son algunas de las razones más repetidas para justificar la compra de una vivienda. Por tanto, la recreación de un vídeo comercial de estas características supone un ejercicio de reconstrucción periodística en la línea de la personalización y tono satírico que caracteriza a este newsgame.

La introducción termina con una de estas interferencias, esta vez apelando directamente al jugador para que viva "la experiencia de ser propietario". Esta presentación informa de la importancia de comprar un piso y, por tanto, prepara la experiencia que se va a plantear para el usuario. En la primera pantalla, debe configurar el tipo de familia y cómo desea vivir: comprar o alquilar una vivienda (figura 2).

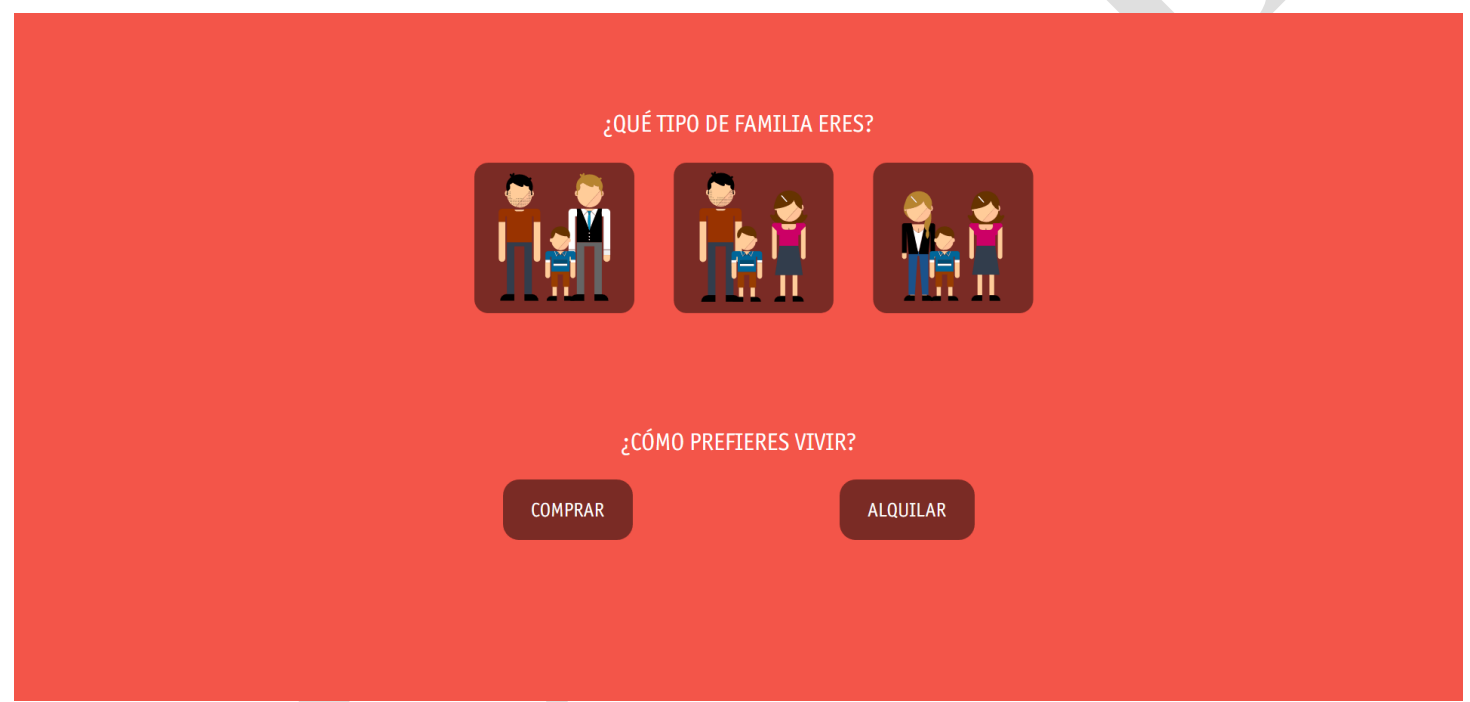

Figura 2: Configuración de familia y tipo de vivienda en Montelab (RTVE.es, 2014)

Esta última elección supone la primera fricción en el gameplay (Pérez Latorre, 2011: 48) de este videojuego informativo: solo se puede avanzar si se elige comprar un piso. Al pulsar la opción de alquilar, aparecen diferentes personajes que aportan razones para adquirir una vivienda en propiedad: "alquilar es tirar el dinero", "comprar un piso es la mejor inversión que he hecho en la vida", "comprar es tener estabilidad"...

Esta tensión entre sujeto y entorno, uno de los ejes que marcan la estructura del videojuego, se hace patente en una simple elección. Montelab no permite alquilar un piso porque la sociedad de la burbuja inmobiliaria tampoco lo permitía, sobre todo mediante mecanismos de presión social. Este newsgame denuncia los problemas de las familias hipotecadas $\mathrm{y}$, por tanto, obliga al jugador a comprar una vivienda al igual que ellas; solo de esta manera puede lograrse una identificación plena. 
Cuando se pulsa el botón de comprar, se abre la interfaz del juego propiamente dicho (figura 3). Se trata de un juego en 2 dimensiones de diseño muy sencillo y con tres variables principales: felicidad, gastos y valor de la vivienda. No se transmite un objetivo claro, sino que se invita a disfrutar de la experiencia: "Vive la experiencia de comprar un piso en plena burbuja inmobiliaria". Una parte muy importante del juego es, por tanto, descubrir las normas conforme avanza la partida.

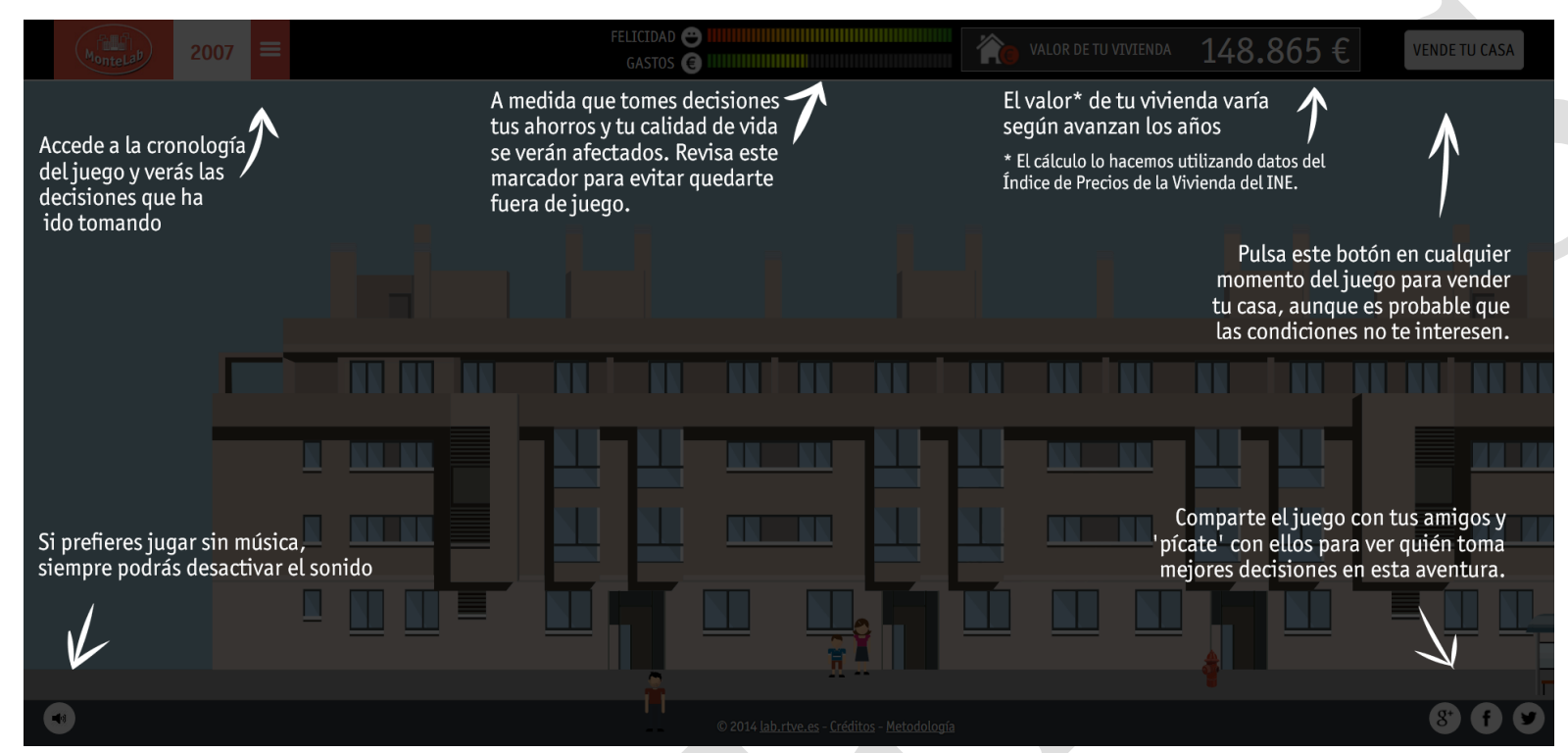

Figura 3: Interfaze instrucciones de Montelab (RTVE.es, 2014)

El jugador encarna a uno de los personajes que componen la familia escogida y, aunque se puede mover al personaje en varias direcciones, la historia solo avanza cuando vamos hacia adelante. Al unirse a su familia, surge una situación sobreimpresa con tres opciones entre las que hay que elegir (figura 4). Este modelo de toma de decisiones es el núcleo central del videojuego, una prueba que se repetirá constantemente y marcará el desarrollo de la historia

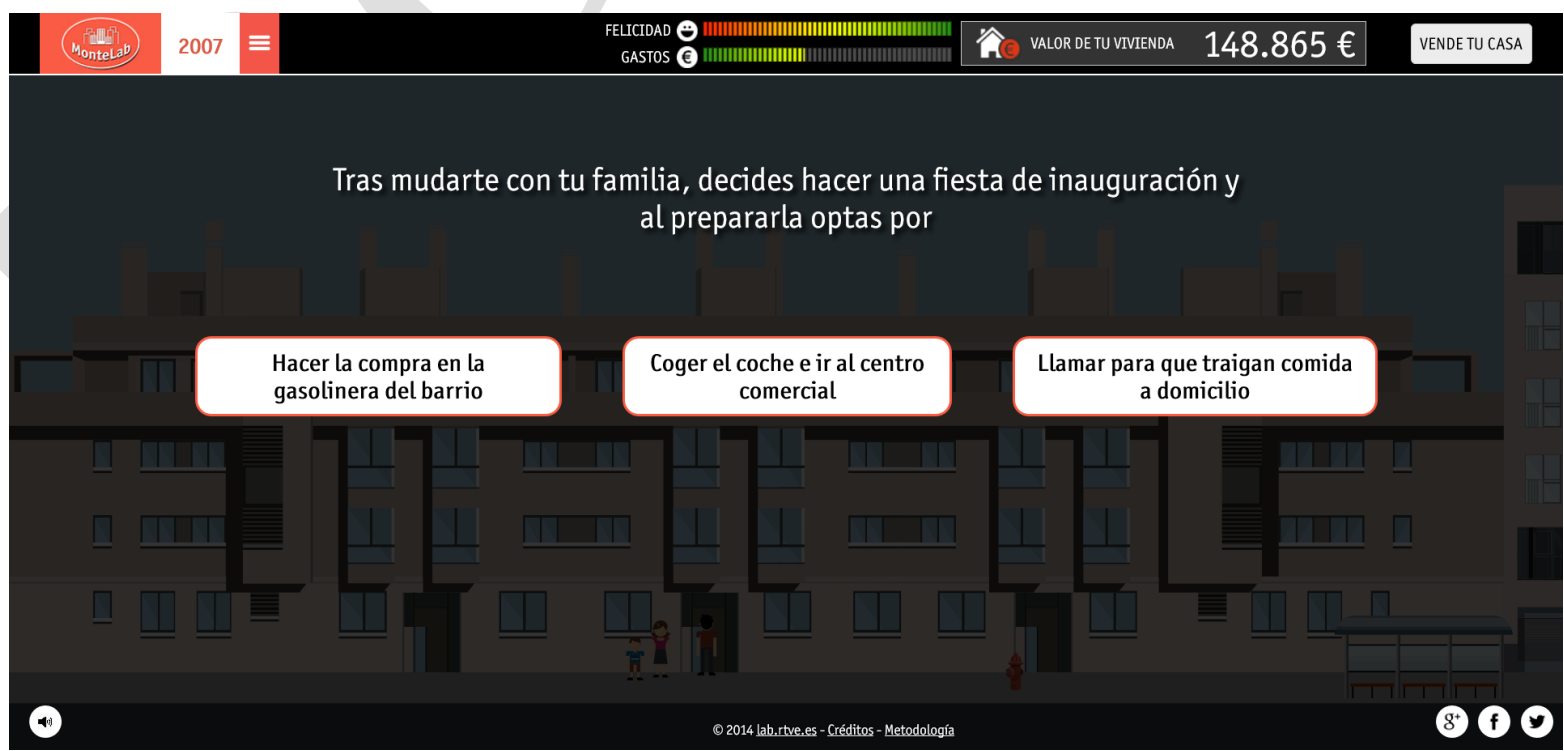

Figura 4: Modelo de toma de decisiones en Montelab (RTVE.es, 2014) 
Según la opción escogida, los niveles de felicidad y gastos variarán; surge de forma implícita el objetivo de mantener ambos indicadores en unos valores aceptables. Las primeras decisiones son fáciles puesto que modifican ligeramente estos parámetros, pero conforme se suceden las rondas aumenta la dificultad. Este incremento se relaciona con la crisis económica, que estalla al poco de comenzar el juego y dificulta la vida de las familias.

Este cambio paulatino supone un eje interesante del lenguaje videolúdico, puesto que une el mundo del relato con la experiencia del jugador: las familias tienen cada vez más problemas para mantener una vida cómoda, al igual que cada elección plantea más contrapartidas para el jugador. Esta relación es un punto muy importante en la construcción del relato videolúdico, puesto que las mecánicas de juego deben ser un reflejo de las acciones que se plantean en la narración, o al menos estar justificadas por esta última. En el caso de Montelab, se trata de un claro ejemplo de cómo utilizar el videojuego para contar una historia con una fuerte carga emocional: el jugador toma unas decisiones que tienen consecuencias, lo que se traduce en un estrés creciente similar al de las familias que sufrieron el pinchazo de la burbuja inmobiliaria.

Los resultados de las elecciones tomadas por el jugador también tienen un fuerte componente periodístico. Cada vez que se toma una opción, no solo se informa de sus consecuencias en el videojuego sino que también se integran estadísticas o testimonios reales sobre personas que se enfrentaron a ese problema en la vida real (figura 5). Queda patente por tanto la inclusión de entrevistas, reportajes o análisis como piezas claramente identificadas dentro del videojuego informativo. Montelab utiliza aquí la experiencia del jugador como locomotora que hace avanzar el relato, incluyendo abundante documentación que ayuda a profundizar en la dimensión personal que puede perderse en el videojuego.

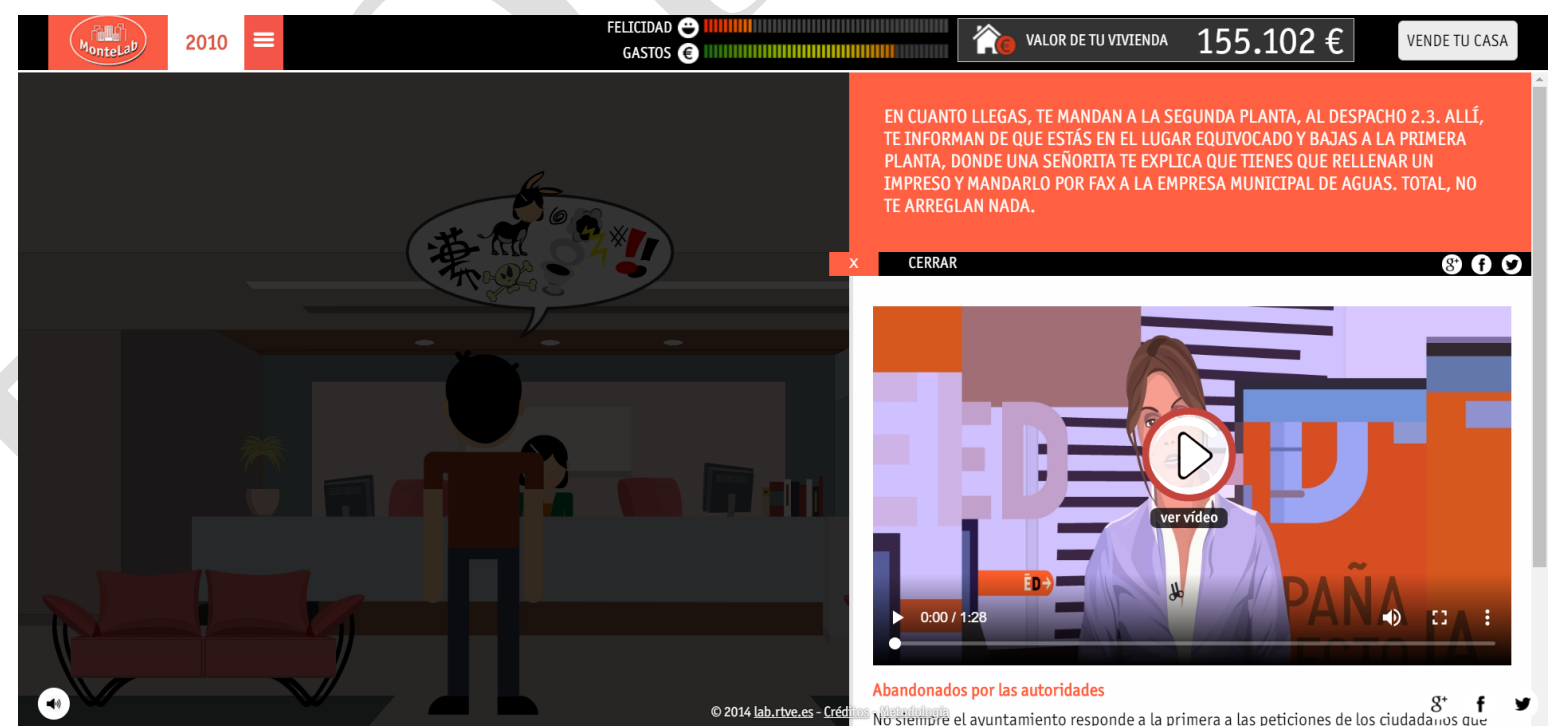

Figura 5: Ejemplo de información y documentación real incluida en Montelab (RTVE.es, 2014)

Las elecciones se siguen sucediendo hasta que el juego termina de tres maneras posibles: los gastos excesivos conducen a la quiebra, el estrés impide seguir adelante o, si los niveles se han 
mantenido dentro de un margen óptimo, el personaje sobrevive a la burbuja inmobiliaria. Al presentar una gran variedad de opciones, Montelab anima al usuario a volver a jugar para analizar las consecuencias de las distintas decisiones.

Sin embargo, esto no significa que haya una variabilidad en el videojuego, puesto que todo ha sido trazado y acotado por los desarrolladores del newsgame, sino que la experiencia de juego es tan amplia que no se puede desbloquear entera en una simple partida. De hecho, el gameplay prototípico comprende jugar varias partidas con decisiones muy diferentes para conocer mejor la problemática que se presenta, tanto en el desarrollo del relato videolúdico como a través de las entrevistas y otras informaciones que acompañan a cada decisión.

\section{Discusión}

Como ha podido comprobarse, Montelab es un rico ejemplo de las posibilidades que plantean los newsgames no solo para contar historias, sino también para ofrecer información complementaria a la publicada por otros medios. Contrariamente a lo que suele pensarse, este videojuego informativo ofrece una rica documentación a lo largo de la partida, sin renunciar por ello a la inmersión que caracteriza a estas narrativas.

Al tratarse de un videojuego, se pueden señalar los cuatro ejes que vertebran el lenguaje de estos medios, si bien algunos aparecen más marcados o tienen mayor importancia que otros. Esto puede ser debido al sistema de juego, propio de los juegos de simulación donde las reglas trazadas por los desarrolladores definen el éxito o fracaso de cada acción.

Este punto es muy importante también desde el punto de vista periodístico, puesto que cada decisión tomada tiene una consecuencia que ha sido decidida por los creadores de Montelab. Por tanto, la subjetividad del periodista no aflora aquí en un punto de vista más o menos personal, sino en el sistema de reglas y recompensas que forma el núcleo del juego. Esta aparente falla es solucionada a través de la publicación de los efectos de cada decisión, de forma que el usuario no solo puede vivir la experiencia del videojuego sino que puede analizar si alguna de estas recompensas está mal ponderada.

Por último, conviene destacar las posibilidades que ofrece el género todavía poco explotado de los newsgames. Frente al auge de los videojuegos caricaturescos que afloraron en los primeros tiempos de internet, ahora nos encontramos videojuegos informativos que no solo presentan interesantes experiencias de juego sino que además prueban nuevas formas de incluir información detallada para no renunciar a un ápice de rigor periodístico.

\section{Referencias bibliográficas}

Aarseth, E. (1997): Cybertext: Perspectives on Ergodic Literature. Baltimore: The John Hopkins University Press

AlADRO, E. (2011): "La teoría de la información ante las nuevas tecnologías de la comunicación", Cuadernos de Información y Comunicación, 16, pp. 83-93. 
Bogost, I. (2010): Newsgames: Journalism at play. Masachussets: The MIT Press.

CANEL, M. J. (1997): "La objetividad periodística en campaña electoral: las actitudes profesionales de los periodistas de TVE1 y Antena3 en las elecciones de 1996", ZER-Revista de Estudios de Comunicación, $2 / 2$.

CHILlón, A. (1999): Literatura y periodismo. Barcelona: Universidad Autónoma de Barcelona.

HARAWAY, D. (1995): “Conocimientos situados: la cuestión científica en el feminismo y el privilegio de la perspectiva parcial" en Ciencia, cyborgs y mujeres. La reinvención de la naturaleza. Madrid, Cátedra, pp. 313-346.

MurRAY, J. (1997): Hamlet en la holocubierta. El futuro de la narrativa en el ciberespacio. Barcelona: Paidós.

Pérez Latorre, O. (2011): El lenguaje videolúdico. Análisis de la significación del videojuego. Barcelona: Laertes.

Peribañez, S. (2017): “Play, don't tell. Hacia una taxonomía de los newsgames en el marco del periodismo transmedia" en Territorios transmedia y narrativas audiovisuales. Barcelona, Editorial UOC, pp. 125-141.

SAN MARTín, R. (2014). "Contra la objetividad. El mito de la neutralidad periodística y las alternativas para repensarlo", Perspectivas De La Comunicación, 1,1, pp. 73-80.

SicarT, M. (2008): «Newsgames: Theory and Design» en Stevens S.M., Saldamarco S.J. (eds) Entertainment Computing - ICEC 2008. ICEC 2008. Lecture Notes in Computer Science, vol 5309. Berlin: Heidelberg.

Tuchman, G. (1998): “La objetividad como ritual estratégico: un análisis de las nociones de objetividad de los periodistas", CIC. Cuadernos De Información Y Comunicación, 0/4, pp. 199218.

VAN DiJK, T. (1990): La noticia como discurso. Barcelona: Paidós. 